\title{
AVALIAÇÃO IN VITRO DA CITOTOXICIDADE DE BRÁQUETES ORTODÔNTICOS CERÂMICOS COM E SEM CANALETA METÁLICA
}

\section{IN VITRO EVALUATION OF THE CYTOTOXICITY OF CERAMIC ORTHODONTIC BRACKETS WITH AND WITHOUT METALLIC SLOT}

\author{
Matheus Melo Pithon* \\ Dandara Andrade de Santana" \\ Rogério Lacerda Santos"** \\ Ricardo Alves de Souza"*** \\ Lívia Maria Andrade de Freitas ${ }^{* \ldots * \ldots}$ \\ Maria Teresa Villela Romanos"*n+*
}

\section{RESUMO}

Introdução: O propósito deste estudo é avaliar a citotoxicidade de bráquetes cerâmicos com e sem canaletas metálicas. Métodos: foram avaliados bráquetes de cerâmica de uma mesma marca comercial (American Orthodontics) distribuídos em dois grupos: 1 -cerâmico com canaleta metálica e 2 - cerâmico convencional. Três grupos-controle foram avaliados: controle positivo $(\mathrm{C}+)$, constituído de um cilindro de amálgama, controle negativo (C-), bastão de vidro, e controle de célula (CC) onde as células não foram expostas a nenhum material. Previamente, os bráquetes foram esterilizados em luz ultravioleta. Após isso, foram imersos em meio mínimo essencial de Eagle por 24 horas, e então procedeu-se à remoção do sobrenadante e colocação em contato com fibroblastos L929. Avaliou-se a citotoxicidade em 4 períodos, 24, 48, 72 e 168 horas. Após contato com o meio, as células foram incubadas por mais 24 horas, quando então foram adicionados $100 \mu$ l do corante vermelho neutro a $0,01 \%$. Passado esse período, foi realizada a contagem de células viáveis em espectrofotômetro em um comprimento de onda de 492nm. Resultados: Não foram encontradas diferenças estatísticas entre os grupos experimentais ( 1 e 2 ) e os grupos-controle negativo e controle de célula ( $p>0.05$ ). O controle positivo foi diferente estatisticamente de todos os outros $(\mathrm{p}<0.05)$. Conclusâo: Os bráquetes de cerâmica avaliados não são citotóxicos.

DESCRITORES: Bráquetes ortodônticos - Testes de Toxicidade - Fibroblastos.

\section{ABSTRACT}

Introduction: The purpose of this study is to evaluate the cytotoxicity of ceramic orthodontic brackets, with or without metallic slot. Methods: Ceramic orthodontic brackets from different commercial brands were examined (American Orthodontics) and divided into two groups: 1- ceramic with metallic slot and 2- conventional ceramic. Three different control groups have been analyzed: positive control $(\mathrm{C}+)$ made of an amalgam barrel, negative control (C-) made of a glass rod and cell control (CC) where the cells were not exposed to any material. First of all, the brackets were sterilized by an ultraviolet light and then immersed in Eagle minimum essential for about 24 hours. The supernatants were collected and their cytotoxicity to L929 fibroblasts where analyzed in 4 periods: 24, 48, 72 and 168 hours. After the contact with the environment, the cells were incubated for another 24 hours and then stained with $100 \mu \mathrm{l}$ of $0,01 \%$ neutral red dye. The viable cells were counted using a spectrophotometer with a wavelength of $492 \mathrm{~nm}$. Results: Any statistics differences have been found among the experimental groups ( 1 and 2 ) and negative control and cell control groups ( $>0.05)$. The positive control group was statistically different from the other groups $(\mathrm{p}<0.05)$. Conclusion: The ceramic orthodontic brackets evaluated are not cytotoxic.

DESCRIPTORS: Orthodontic brackets - Toxicity tests - Fibroblasts.

* Mestre e Doutor em Ortodontia pela Universidade Federal do Rio de Janeiro - UFRJ. Professor de Ortodontia da Universidade Estadual do Sudoeste da Bahia - UESB. mateuspithon@gmail.com

** Acadêmica de Odontologia da Universidade Estadual do Sudoeste da Bahia - UESB. andradedandara@gmail.com

*** Mestre e Doutor em Ortodontia pela Universidade Federal do Rio de Janeiro - UFRJ. Professor de Ortodontia da Universidade Federal de Campina Grande-UFC. lacedaorto@hotmail.com

**** Mestre em Ortodontia pela Universidade Estadual de Campinas - FOP-UNICAMP. Professor de Ortodontia da Universidade Estadual do Sudoeste da Bahia - UESB. ricardoalves@fop.unicamp.br

***** Mestre e Doutora em Ortodontia pela Faculdade de Odontologia de Bauru - FOB/USP. Professora de Ortodontia da Universidade Estadual do Sudoeste da Bahia - UESB. livifret@yahoo.com.br

****** Mestre e Doutora em Microbiologia pela Universidade Federal do Rio de Janeiro - UFRJ. Professora de Virologia da Universidade Federal do Rio de Janeiro -UFRJ. teresa.romanos@micro.ufrj.br 
PITHON MM :

SANTANA DA

SANTOS RL

SOUZA RA

FREITAS LMA

ROMANOS MTV

AVALIAÇÃO

IN VITRO DA

CITOTOXICIDADE

DE BRÁQUETES

ORTODONTICOS

CERATMICOS COM

E SEM CANALETA

METÁLICA

$224 \ldots$

REV, ODONTOL.

UNIV. CID, SÃO

PAULO

$2011 ; 23(3): 223-$

7 , SET-DEZ

\section{N T RO DUÇ ÃO}

O comportamento biológico dos materiais odontológicos tem despertado interesse entre os pesquisadores no desenvolvimento de características biocompatíveis em meio bucal (Jorge et al. $\left.{ }^{1}, 2004\right)$. A capacidade de um material de desempenhar suas funções específicas, sem causar danos ou prejuízo, quando exposto em tecidos vivos, é o que pode ser definido como biocompatibilidade (Costa $\left.{ }^{2}, 2001\right)$.

Na Odontologia, o aparelho ortodôntico é composto por diversos tipos de materiais que permanecem em contato com a cavidade oral por longos períodos de tempo, a exemplo das resinas, fios e bráquetes. Os bráquetes estão disponíveis no mercado nas composições metálica, plástica e cerâmica, e alterações nas propriedades desses materiais podem acarretar efeitos nocivos sobre os tecidos bucais, levando ao desenvolvimento de processos inflamatórios (Pithon et al. ${ }^{3}, 2009$ ).

Os bráquetes cerâmicos, considerados estéticos ao imitar a cor do dente, possuem dois tipos de arranjo: monocristalina e policristalina Os bráquetes cerâmicos policristalinos são formados de cristais de óxido de alumínio fusionados a altas temperaturas, o que admite a moldagem de vários bráquetes ao mesmo tempo, enquanto que os bráquetes de cerâmica monocristalina são moldados um por vez, pois constituem-se em uma massa fundida a alta temperatura, formando um único cristal de óxido de alumínio (Maltagliati et al. $\left.{ }^{4}, 2003\right)$.

Apesar da característica estética como vantagem, os bráquetes cerâmicos apresentam alto coeficiente de fricção, o que atrapalha o nível de força da movimentação ortodôntica, pois a dificuldade de polimento das superfícies rugosas do bráquete afeta o deslizamento do fio em contato com esse acessório (Nishio et al. ${ }^{5}$, 2004). A fim de equilibrar os problemas friccionais, canaletas metálicas foram adicionadas aos bráquetes cerâmicos, assim a maior lisura de superfície e o arredondamento das bordas facilitam o deslize dos fios (Kapur Wadhwa et al. ${ }^{6}, 2004$ ).

No meio oral, a cerâmica e a canaleta de metal dos bráquetes criam um dina- mismo com os tecidos bucais e a saliva. Essa interação pode resultar na biocompatibilidade com os acessórios ortodônticos ou mesmo provocar citotoxicidade aos tecidos vivos, se houver liberação de elementos materiais. Portanto, o objetivo desta pesquisa é avaliar a citotoxicidade de bráquetes cerâmicos com e sem canaletas metálicas.

\section{MÉTODOS}

\section{Cultura de células}

A linhagem celular utilizada foi L929, obtida do American Type Culture Collection (ATCC, Rockville, MD) (fibroblasto de camundongo), cultivada em meio mínimo essencial de Eagle (MEM) (Cultilab, Campinas, São Paulo, Brazil) suplementado com 2 mM de L-glutamina (Sigma, St. Louis, Missouri, USA), $50 \mathrm{mg} / \mathrm{ml}$ de gentamicina (Schering Plough, Kenilworth, New Jersey, USA), 2,5 mg/ml de fungizona (Bristol-Myers-Squibb, New York, USA), $0.25 \mathrm{ml}$ solução de bicarbonato de sódio (Merck, Darmstadt, Germany), 10 mM de HEPES (Sigma, St. Louis, Missouri, USA), e $10 \%$ de soro fetal bovino (SFB) (Cultilab, Campinas, São Paulo, Brazil) e mantida a 37 0C em ambiente contendo $5 \%$ de $\mathrm{CO} 2$.

\section{Bráquetes avaliados}

A amostra constituiu-se de bráquetes cerâmicos com e sem canaletas metálicas (American Orthodontics, Sheboygan, EUA).

\section{Controles}

Para verificar a resposta celular perante os extremos, três grupos-controle foram avaliados, grupo CC (controle de célula), onde as células não foram expostas a nenhum material, grupo $\mathrm{C}+$ (controle positivo), constituído de um cilindro de amálgama e C- (controle negativo), no qual um bastão de vidro ficou em contato com as células.

Ensaio de citotoxicidade dos materiais

Os materiais foram esterilizados previamente por exposição à luz U.V. (Labconco, Kansas, Missouri, USA) durante 1 hora. Em seguida, três amostras de cada material foram colocadas em placas de 24 
poços contendo meio de cultura (MEM) (Cultilab, Campinas, São Paulo, Brazil). A cada 24 horas, o meio de cultura foi substituído por meio novo e os sobrenadantes coletados após 24, 48, 72 e 168 horas (7dias), e avaliados quanto à toxicidade para as células L929. Os sobrenadantes foram colocados, em triplicata, em uma placa de 96 poços contendo monocamada confluente de L929 e incubados por 24 horas a 37 0C em ambiente contendo $5 \%$ de CO2. Terminado o tempo de incubação, o efeito na viabilidade celular foi determinado através da técnica "dye-uptake", descrita por Neyndorff et al. ", (1990), com pequenas modificações. Ou seja, após 24 horas de incubação, foram adicionados $100 \mu \mathrm{l}$ de vermelho neutro a 0,01\% (Sigma, St. Louis, Missouri, USA), em meio de cultura, em cada poço das microplacas e estas foram incubadas a $37 \mathrm{oC}$ por 3 horas para penetração do corante nas células vivas. Passado esse período, após desprezar o corante, foram adicionados $100 \mu$ l de solução de formaldeído (Reagen) a 4\% em PBS ( $\mathrm{NaCl} 130$ mM; $\mathrm{KCl} 2 \mathrm{mM}$; Na2HPO4 2H2O 6 mM; K2HPO4 $1 \mathrm{mM}, \mathrm{pH} 7,2)$ por 5 minutos, para promover a fixação das células às placas. Em seguida, para a extração do corante, foram adicionados $100 \mu$ l de uma solução de ácido acético (Vetec, Rio de Janeiro, Brasil) a 1\% com metanol (Reagen, Rio de Janeiro, Brasil) a 50\%. Após 20 minutos a leitura foi realizada em espectrofotômetro (BioTek, Winooski, Vermont, USA) em um comprimento de onda de 492nm ( $\mu=492$ $\mathrm{nm})$.

\section{Análise estatística}

As análises estatísticas foram realizadas com auxílio do programa SPSS 13.0 (SPSS Inc.,Chicago, Illinois, EUA). Análise estatística descritiva incluindo média e desvio-padrão foi calculada para os grupos avaliados. Os valores da quantidade de células viáveis foram submetidos à análise de variância (ANOVA) para determinar se havia diferenças estatísticas entre os grupos, e posteriormente ao teste de Tukey.

\section{RESULTADOS}

Os resultados obtidos quanto à citotoxicidade dos bráquetes de cerâmica estão descritos na Tabela 1.

Não houve diferenças estatisticamente significativas entre os grupos experimentais em relação ao grupo-controle positivo e o grupo de controle celular durante os perídos de 1, 2, 3 e 7 dias. No fim do sétimo dia, os bráquetes apresentaram baixa citotoxicidade, não havendo diferenças estatisticamente significativas entre si e entre os grupos de controle ao final do experimento. O grupo-controle positivo mostrou níveis elevados de citotoxicidade durante todo o período do estudo.

Tabela 1. Média, desvio-padrão e análise estatística dos valores de células viáveis para os grupos estudados.

\begin{tabular}{|c|c|c|c|c|c|c|c|c|}
\hline & $24 \mathrm{hrs}$ & & $48 \mathrm{hrs}$ & & $72 \mathrm{hrs}$ & & $168 \mathrm{hrs}$ & \\
\hline & Média/DP & Est. & Média/DP & Est. & Média/DP & Est. & Média/DP & Est. \\
\hline $\begin{array}{l}\text { Com canaleta } \\
\text { metálica }\end{array}$ & $\begin{array}{l}451,2 \\
(79,1)\end{array}$ & $A$ & $\begin{array}{l}538,2 \\
(166,8)\end{array}$ & $A$ & $\begin{array}{l}308,8 \\
(25,2)\end{array}$ & $A$ & $\begin{array}{l}981,2 \\
(118,5)\end{array}$ & $A$ \\
\hline Cerâmico puro & $\begin{array}{l}490,8 \\
(42,2)\end{array}$ & $A$ & $\begin{array}{l}551,3 \\
(109,8)\end{array}$ & $A$ & $\begin{array}{l}306,5 \\
(38,09)\end{array}$ & $A$ & $\begin{array}{l}1028,1 \\
(27,4)\end{array}$ & $A$ \\
\hline$C C$ & $\begin{array}{l}532,6 \\
(31,7)\end{array}$ & $A$ & $579(126,2)$ & $A$ & $\begin{array}{l}319,6 \\
(18,8)\end{array}$ & $A$ & $\begin{array}{l}1041,3 \\
(81,03)\end{array}$ & $A$ \\
\hline$C+$ & $\begin{array}{l}274,6 \\
(62,2)\end{array}$ & $B$ & $251,6(50,2)$ & $B$ & $\begin{array}{l}212,6 \\
(37,8)\end{array}$ & $B$ & $\begin{array}{l}648,3 \\
(49,3)\end{array}$ & $B$ \\
\hline$C-$ & $\begin{array}{l}539 \\
(6,06) \\
\end{array}$ & $A$ & $513,3(35,6)$ & $A$ & $318(26,8)$ & $A$ & $\begin{array}{l}951,6 \\
(55,5) \\
\end{array}$ & $A$ \\
\hline
\end{tabular}

Est. = análise estatística onde letras iguais correspondem à ausência de diferenças estatísticas $(P>0.05)$. $\mathrm{DP}=$ desvio- padrão.

PITHON MM
SANTANA DA
SANTOS RL
SOUZA RA
FREITAS LMA
ROMANOS MTV
AVALIAÇÃO
IN VITRO DA
CITOTOXICIDADE
DE BRÁQUETES
ORTODONTICOS
CERÂMICOS COM
E SEM CANALETA
METÁLICA 
PITHON MM :

SANTANA DA

SANTOS RL

SOUZA RA

FREITAS LMA

ROMANOS MTV

AVALIAÇÃO

IN VITRO DA

CITOTOXICIDADE

DE BRÁQUETES

ORTODONTICOS

CERATMICOS COM

E SEM CANALETA

METÁLICA

$226 \ldots$

REV, ODONTOL :

UNIV. CID. SÃO

PAULO

$2011 ; 23(3): 223-$

7 , SET-DEZ

\section{I SCUSSÃO}

A utilização de materiais biocompatíveis é essencial para garantir um tratamento biologicamente seguro (Montanaro et al. $\left.{ }^{8}, 2005\right)$. Por apresentar interação com os tecidos e fluidos bucais por períodos de tempo, é muito importante a realização de pesquisas que investiguem os efeitos biológicos dos materiais odontológicos. O teste de citotoxicidade in vitro é a primeira escolha para avaliar a biocompatibilidade de qualquer material para uso biomédico, como propõe a International Standard Organization, ISO 10993 (International ${ }^{9}$, 1999). Na Ortodontia, os bráquetes em contato com os tecidos orais e saliva podem sofrer modificações em suas propriedades e implicar em consequências deletérias ao organismo. Dessa forma, o presente estudo avaliou a citotoxicidade de bráquetes ortodônticos cerâmicos com e sem canaleta metálica; estes ao apresentarem a característica estética têm sido muito utilizados no tratamento ortodôntico.

A citotoxicidade dos bráquetes foi avaliada pelo método de incorporação do vermelho neutro, considerado um teste in vitro efetivo, de baixo custo, reprodutível e quantitativo para selecionar substâncias potencialmente tóxicas (Daguano et $\left.a l .{ }^{10}, 2007\right)$. O vermelho neutro é um corante solúvel em água, o que favorece o transpasse pela membrana celular, concentrando-se nos lisossomos, onde se fixa por ligações eletrostáticas hidrofóbicas em sítios aniônicos na matriz lisossomal (Rogero et al. ${ }^{11}, 2003$ ). Assim foi possível destacar as agressões celulares e realizar a contagem dos fibroblastos L929 viáveis por meio da espectofotometria, uma vez que as alterações celulares diminuem a absorção do corante vital vermelho neutro.

Os materiais odontológicos e sua toxi- cidade sempre foi tema de grandes estudos, inclusive na Ortodontia. Kao et al. ${ }^{12}$ (2007) avaliaram os efeitos citotóxicos de quatro diferentes bráquetes ortodônticos metálicos em meios de imersão, e, apesar das alterações celulares apresentadas, os bráquetes puderam ser considerados biocompatíveis. Pithon et al. ${ }^{13}$ (2008) avaliaram a citotoxicidade de quatro diferentes marcas comerciais de elásticos intermaxilares intraorais em meio celular, e, quando comparados os resultados entre si, observou-se ausência de toxicidade dos elásticos das marcas American Orthodontic e 3M Unitek. Contudo, concluiu-se que os elásticos das marcas Morelli e Uniden demonstraram alta citotoxicidade (Pithon et al. ${ }^{13}$, 2008).

O teste de citotoxicidade utilizando o método da cultura de fribroblastos L929 e corante vermelho neutro permitiu determinar o desempenho biocompatível dos bráquetes cerâmicos ortodônticos com e sem canaleta metálica durante o período de tempo estudado. Em todos os períodos $(24,48,72$ e 168 horas) não houve diferenças estatisticamente significativas entre os grupos experimentais e os grupos-controle, apenas o grupo-controle positivo mostrou alto índice de citotoxicidade.

Contudo, o período de avaliação de 7 dias é curto quando comparado ao tempo real de um tratamento ortodôntico, que dura meses. Portanto, faz-se necessário um outro estudo para avaliar a citotoxicidade desses bráquetes a longo prazo.

\section{CONCLUSÃO}

Ao final, pode-se concluir que os bráquetes ortodônticos de cerâmica com e sem canaleta metálica não são citotóxicos nos períodos de tempo avaliados neste estudo. Portanto, esses materiais são considerados seguros para uso clínico nesse período de tempo. 
PITHON MM

SANTANA DA

SANTOS RL

SOUZA RA

FREITAS LMA

ROMANOS MTV

A VALIAÇÃO

IN VITRO DA

CITOTOXICIDADE

DE BRÁQUETES

ORTODONTICOS

CERAMICOS COM

E SEM CANALETA

METÁLICA

4. Maltagliati LÁ, Feres R, Figueiredto MA, Siqueira DF. Braquetes estéticos: considerações clínicas. Rev Clín Ortodon Dental Press 2003 jun.-jul.;5(3):84-7.

5. Nishio C, da Motta AF, Elias CN, Mucha JN. In vitro evaluation of frictional forces between archwires and ceramic brackets. Am J Orthod Dentofacial Orthop 2004 Jan;125(1):56-64.

6. Kapur Wadhwa R, Kwon HK, Close JM. Frictional resistances of different bracket-wire combinations. Aust Orthod J 2004 May;20(1):25-30.

7. Neyndorff HC, Bartel DL, Tufaro F, Levy JG. Development of a model to demonstrate photosensitizer-mediated viral inactivation in blood. Transfusion 1990 Jul-Aug;30(6):485-90.

8. Montanaro L, Cervellati M, Campoccia D, Prati C, Breschi L, Arciola CR. No genotoxicity of a new nickel-free stainless steel. Int J Artif Organs 2005 Jan;28(1):58-65.

9. International S. Biological evaluation of medical devices Part 5: tests for in vitro cytotoxicity. 1999 [cited 201131 de maio]; 2:[Available from: http://doc.isiri.org.ir/c/ document_library/get_file?p_l_id=1 8496\&folderld=20864\&name=DLFE-30087. pdf],.

10. Daguano JKMF, Santos C, Rogero SO. Avaliação da citotoxicidade de biocerâmicas desenvolvidas para uso em sistemas de implantes. Matéria (Rio de Janeiro) 2007 12(134-9.

11. Rogero SO, Lugão AB, Ikeda TI, Cruz ÁS. Teste in vitro de citotoxicidade: estudo comparativo entre duas metodologias. Materials Research 2003 6(317-20.

12. Kao CT, Ding SJ, Min Y, Hsu TC, Chou MY, Huang TH. The cytotoxicity of orthodontic metal bracket immersion media. Eur J Orthod 2007 Apr;29(2):198-203.

13. Pithon MM, Santos RL, Ruellas AC, Sant'Anna EF, Romanos MTV, Silva-Mendes G. Avaliação in vitro da citotoxicidade de elásticos ortodônticos intermaxilares. Rev Odonto Ciênc 2008 jul.-set.;23(3):287-90.

Recebido em: 05/09/2011

Aceito em: 15/09/2011 